\title{
A atenção domiciliar como estratégia para ampliação das relações de convivência de pessoas com deficiências físicas*
}

\section{Domiciliary care as a strategy for expanding the social relations of people with physical disabilities}

\author{
Taísa Gomes Ferreira ${ }^{1}$, Fátima Corrêa Oliver ${ }^{2}$
}

\begin{abstract}
FERREIRA, T. G.; OLIVER, F. C. A atenção domiciliar como estratégia para ampliação das relações de convivência de pessoas com deficiências físicas. Rev. Ter. Ocup. Univ. São Paulo, v. 21, n. 3, p. 189-197, set./dez. 2010.

RESUMO: Neste estudo se discute a atenção domiciliar como estratégia para facilitar oportunidades de convivência de pessoas com deficiências físicas. Partiu-se da hipótese de que após a aquisição da deficiência as pessoas têm menores oportunidades de exercitar a convivência, considerada como a possibilidade de estar junto, entre e em relação com algo ou alguém, que pode ser fonte de bem-estar e auxiliar a adaptação da pessoa à condição de vida com deficiência. Pretendese discutir a importância das relações de convivência das pessoas com deficiência e da atenção domiciliar como estratégia que possibilita o conhecimento e ampliação destas relações. Foram estudadas histórias de vida de 4 adultos com deficiências físicas adquiridas, moradores da área de abrangência de serviço de atenção básica de saúde no município de São Paulo, que representavam, em gênero, idade e tipo de deficiência, as pessoas com deficiências identificadas na unidade. As histórias de vida foram transcritas e analisadas buscando conhecer a importância da convivência nos períodos antes e depois da aquisição da deficiência. A análise dos dados baseou-se na teoria de rede social significativa. A diminuição das relações de convivência pelo afastamento do trabalho e menor circulação foram determinantes da condição da pessoa após a deficiência. A compreensão de deficiência como condição social possibilita considerar a atenção domiciliar como proposta de intervenção, que pode promover a diminuição do isolamento, a ampliação das redes sociais e de suporte e a criação de possibilidades de circulação social, que podem ser considerados desdobramentos do ato de conviver.
\end{abstract}

DESCRITORES: Terapia ocupacional; Visita Domiciliar; Pessoas com deficiência.

\footnotetext{
* Este artigo apresenta parte da reflexão da pesquisa de mestrado intitulada "Pessoas com deficiências: condições de convivência e possibilidade de atenção domiciliar".

1. Terapeuta Ocupacional. Colaboradora do Laboratório de Reabilitação com Ênfase no Território. Mestre em Ciências pela FMUSP.

2. Docente do Depto. de Fisioterapia, Fonoaudiologia e Terapia Ocupacional da FMUSP. Doutora em Saúde Pública.

Endereço para correspondência: Departamento de Fisioterapia, Fonoaudiologia e Terapia Ocupacional da FMUSP. Rua Cipotânea, 51, Cidade Universitária, São Paulo, SP. CEP 05360-160
} 


\section{INTRODUÇÃO}

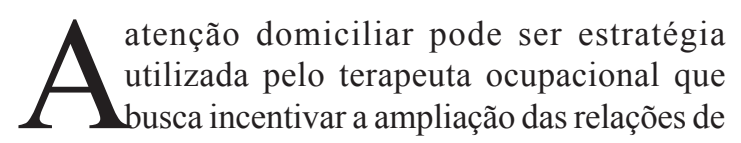
convivência de pessoas com deficiências físicas, que neste artigo, está apoiada na discussão do que é a "convivência" e sua relação com a aquisição da deficiência física realizada na pesquisa aqui apresentada.

A convivência é o resultado da ação de estar junto, entre e em relação com algo ou alguém, não necessariamente conhecido. Permite a partilha do cotidiano e a participação na vida de outros (DOIMO et al., 2008).

Através do convívio diário é possível transitar por diferentes espaços sociais, sair de nós mesmos para caminhar pelo desconhecido, sentir os prazeres e dificuldades da vida coletiva. Assim sendo, é possível estabelecer conexões, que permitem às pessoas a diminuição das situações de isolamento, e a inclusão em um conjunto, onde se pode compartilhar determinados valores e novas maneiras de viver e de se expressar.

A convivência num sentido poético brinda a troca de olhares, novas sensações (boas e ruins), traz oportunidades de fazer comparações, de conhecer, compartilhar histórias, momentos, cenas, linguagens, que podem "favorecer o aumento da vivência existencial" (ROGERS, 1991) e ampliar experiências capazes de agregar sentido à vida. Permite também a expressão da criatividade e a ampliação das relações sociais, que se configuram como significativas também para as pessoas que adquirem a deficiência em algum momento de sua vida.

Através da convivência, as pessoas com deficiências físicas adquiridas têm a possibilidade de criar estratégias para lidar com as diferentes situações de vida (negativas e ou positivas, vinculadas ou não com a deficiência) que podem influenciar a construção da identidade de "ser deficiente", já que ao circular socialmente se vivenciam situações, onde a diferença se sobressai, há exposição ao preconceito, aos olhares curiosos sobre a deficiência e se revelam as capacidades, muitas vezes desconhecidas pela maioria das pessoas.

A relação entre convivência e deficiência física é pouco discutida na literatura. É mais frequente encontrar discussões, que ressaltam a importância das relações sociais para a adaptação à nova condição de vida após a aquisição da deficiência e sua relevância na ampliação das condições de saúde, já que por meio destas relações se obtêm auxílio para acessar diferentes equipamentos sociais, onde é possível o exercício da convivência (SLUZKI, 1997; AVALUND, 2004; COHEN, 2004; FERREIRA, 2009).
A convivência e as relações sociais não devem ser consideradas sinônimos, pois, como exposto acima, o ato de conviver possibilita além da ampliação e conservação das relações sociais, a possibilidade de expressão e apreensão de novas sensações e experiências, que podem ampliar o universo de significação dos indivíduos e torná-los ainda mais diferentes do que são.

Um exemplo simples vindo de uma situação que para muitos é corriqueira: ao transitar pelas ruas, se pode observar um jeito diferente de se vestir, uma nova expressão ou maneira diferente de se portar que talvez possa inspirar mudanças, ou apenas questionamentos e/ou comentários com as pessoas sobre outros aspectos da vida, gerando assim, pelo simples fato de estar entre outros, situações que ampliam as possibilidades de "estar" no mundo.

Essa discussão se faz importante, pois, quando a análise das consequências da deficiência é ampliada para além das questões das incapacidades físicas, pode se perceber que, além das perdas motoras, a pessoa com deficiência física experimenta, por vezes, também o empobrecimento da sua rede social chegando a situações de isolamento, onde a impossibilidade de exercitar sua circulação com autonomia causa um impacto direto nas relações de convivência estabelecidas.

Assim sendo, pessoas com deficiências físicas adquiridas, que antes da deficiência tinham estabelecido suas relações de convivência, podem vivenciar uma drástica redução destas, pois como veremos adiante, é comum a vivência de impedimentos à participação e à circulação, que influenciam a quantidade e a qualidade dessas relações.

Para lidar mais especificamente com as questões advindas do campo "convivência" acredita-se que iniciativas assistenciais, que se fundamentam em princípios como da equiparação de oportunidades e de inserção comunitária podem subsidiar ações mais eficazes que, por sua vez, podem ampliar ou restabelecer as relações de convivência.

Uma das maneiras possíveis para se construir uma intervenção, que objetive a ampliação das relações de convivência seria através da atenção domiciliar, pois esta estratégia possibilita uma aproximação natural do terapeuta com o lugar de vida da pessoa com deficiência trazendo assim elementos importantes à intervenção, que possibilitarão ao terapeuta contextualizar as necessidades e construir uma atuação junto e para a pessoa com deficiência.

\section{Apontamentos sobre a atenção domiciliar}

O Ministério da Saúde brasileiro considera que a atenção domiciliar abrange diferentes níveis de cuidado (atenção primária, secundária e terciária) e compreende 
ações de promoção, prevenção e reabilitação (BRASIL, 2006). É importante salientar as diferenças entre, a atenção domiciliar, (mais geral) e o atendimento domiciliar, (mais específico) que compreende a assistência domiciliar e a internação domiciliar, já que cada uma possui características peculiares, que as diferenciam e são imperativas na orientação e na execução das práticas profissionais.

A atenção domiciliar pode ser considerada como "um dos meios de se obter do indivíduo, da família e da comunidade sua participação no planejamento, organização, operação e controle" dos cuidados em saúde (MAZZA, 2004, p. 1), utilizando-se dos recursos locais disponíveis. Representa também uma alternativa de cuidado à saúde, que visa assegurar o direito e a equidade na assistência de pessoas, que sobreviveram a doenças crônicas e degenerativas e às conseqüências na saúde de situações de violência, muitas vezes, com sequelas, que dificultam a locomoção e o acesso aos serviços (GASPAR et al., 2007).

Esta opção pode ser aplicável à realidade brasileira, principalmente à das grandes metrópoles, onde o acesso aos serviços, que realizam o acompanhamento de pessoas com deficiência física ainda é precário. Esta maneira de intervir aproxima profissionais e serviços das questões do contexto territorial, que podem ser essenciais para nortear a conduta do profissional, tais como cultura, acessibilidade, disponibilidade de equipamentos de saúde, educação e de lazer.

Além disso, segundo Doimo et al. (2008), a atenção domiciliar permite um diagnóstico mais rápido e específico do ambiente e do modo de vida da pessoa com deficiência, possibilitando assim um ajuste das intervenções e de recursos, que se encontram disponíveis na comunidade. Deste modo, os procedimentos focalizam a condição da pessoa, de sua família e na comunidade.

Para Lacerda et al. (2006), o fato de a atenção abranger o cliente e sua família permite que os profissionais desenvolvam atividades de modo a auxiliá-los a compreender os fatores, que colocam em risco sua saúde, bem como contribuir para melhorar sua qualidade de vida.

Assim sendo, as intervenções podem ser realizadas a partir da compreensão de que o sujeito a ser acompanhado é parte de um contexto sociocultural complexo (ALMEIDA, 2000). A meta, em curto prazo, é auxiliar o indivíduo a se ajustar à sua nova condição intercedendo em diferentes instâncias contextualizadas em ordem de importância (sob o ponto de vista da pessoa) para que ele sinta-se seguro para, por exemplo, conquistar novas oportunidades para conviver.

A partir da compreensão de que pessoas com deficiências físicas sofrem impedimentos que dificultam sua vivencia em sociedade, se propõe a atenção domiciliar como intervenção, que promova diminuição do isolamento, ampliação das redes sociais e de suporte, criação de possibilidades de circulação social e aumento da visibilidade social da pessoa com deficiência (muitas vezes limitada pelas condições socioculturais e geográficas do território) para que assim consigam criar mecanismos compensatórios e de proteção para modificar a situação de isolamento em que se encontram.

Este estudo buscou conhecer os processos de aquisição de deficiência física entre adultos e discutir as suas repercussões nas relações de convivência, bem como considerar a atenção domiciliar como uma proposta de intervenção em terapia ocupacional que contribua para a ampliação dessas relações e assim favorecer a qualidade de vida das pessoas e seus familiares.

\section{MATERIAIS E MÉTODOS}

O estudo foi realizado entre os anos de 2006 e 2007 e para o seu desenvolvimento foi escolhida a abordagem qualitativa para coleta e análise dos dados, pois nele se buscou avaliar como é do ponto de vista da pessoa com deficiência a experiência de ser deficiente e o quão impactante foi ou é essa condição em sua vida, principalmente, no que diz respeito às necessidades de convivência.

Para a pesquisa privilegiou-se conhecer histórias de vida de adultos a partir de entrevista narrativa, que torna possível à pesquisadora estabelecer um vínculo entre as relações de convivência e a condição da deficiência na vida diária, que, segundo Meletti, (2003) são pouco descritas na literatura, onde, na maioria das vezes, se descrevem os problemas funcionais e de desempenho relacionados à incapacidade da pessoa, permanecendo os problemas relacionados à deficiência restritos a essa descrição.

Pantano (1987), em seu trabalho visando compreender a deficiência como um problema social, sustenta que "é necessário conhecer a definição que as pessoas com deficiências fazem de si mesmas porque é esse, o plano de ideias e de concepções, um dos pontos de partida da ação" (p. 62-63), o que poderia ser realizado pela história de vida.

Essa abordagem metodológica possibilita conhecer o ponto de vista do sujeito, já que o pesquisador se propõe a ouvir o que o sujeito tem a dizer sobre ele mesmo: o que ele acredita que seja importante sobre sua vida (GLAT, 1989). Desta maneira, através do "contar sua história" o sujeito além de narrar os acontecimentos tem também a oportunidade de refletir sobre estes enquanto os descreve.

A opção de realizar a coleta dos dados por meio de história de vida se baseou, sobretudo, no fato de que ela "reconstrói ações" e contexto, pois por meio dela busca-se captar o lugar, o tempo, a motivação e as orientações do sistema simbólico do ator (JOVCHELOVITCH; BAUER, 2002). 
No caso desta pesquisa foi essencial para estabelecer uma compreensão da trajetória de vida a partir do ponto de vista da pessoa com deficiência.

$\mathrm{O}$ estudo se deu entre moradores da região de abrangência de uma Unidade Básica de Saúde (UBS) num bairro periférico da cidade São Paulo, que conta com seis equipes de Saúde da Família e onde se desenvolve projeto de atuação comunitário e territorial em reabilitação e terapia ocupacional.

A coleta de dados teve início após a aprovação do projeto de pesquisa pelos Comitês de Ética em Pesquisa da Secretaria Municipal de Saúde de São Paulo (Processo 137/06) e da Faculdade de Medicina da Universidade de São Paulo (Processo 830/06).

Procurou-se representar as pessoas com deficiência acompanhadas na UBS, no que diz respeito à idade, etiologia da deficiência e sequelas a partir de estudo dos prontuários das pessoas com deficiências, já identificadas no serviço. Excluíram-se as pessoas que recebiam atendimentos domiciliares por terapeutas ocupacionais ou já participassem do grupo de convivência na UBS, pois era objetivo compreender como essas pessoas organizaram suas vidas após a aquisição da deficiência sem o auxílio da terapia ocupacional.

Participaram do estudo quatro pessoas, sendo um homem e três mulheres com idades entre 29 e 67 anos. Consideraram-se pessoas com sequelas incapacitantes decorrentes de diferentes etiologias (ortopédicas, neurológicas e vasculares) respeitando os critérios descritos anteriormente.

Os sujeitos foram localizados através da aproximação da pesquisadora e os profissionais da UBS que a acompanharam até a casa das pessoas entrevistadas a fim de apresentá-la e assim, formalizar o contato para o estudo.

As entrevistas foram realizadas no domicílio das pessoas e durante sua execução buscou-se explorar a trajetória de vida da pessoa com deficiência, sua percepção das necessidades, experiência na assistência em saúde e reabilitação, rede social e de suporte e a participação na vida social e exercício de direitos.

Após a escuta e transcrição das entrevistas, realizouse sua análise com objetivo de conhecer as relações de convivência estabelecidas e um dos parâmetros utilizados para levantar as categorias de análise foi a rede social significativa (SLUZKI, 1997). As quatro categorias estabelecidas foram "família", "amigos", "relações de trabalho" "práticas sociais e inserção comunitária", que subsidiaram a discussão sobre "relações de convivência", "rotina" (no trabalho, lar e tempo livre) e "experiência da aquisição da deficiência".

Neste artigo, será privilegiada a discussão entre a atenção domiciliar e as relações de convivência, parte da dissertação.

\section{Breve apresentação dos entrevistados}

Foram adotados nomes fictícios a fim de preservar a identidade dos entrevistados e facilitar a vinculação de sua história com os dados apresentados nos próximos tópicos.

Shin, com 67 anos, é filho de imigrantes japoneses. Casado e com quatro filhos. Como antes do Acidente Vascular Encefálico (AVE) o trabalho assumia posição central em sua vida, suas relações de convivência eram basicamente provenientes de sua rotina de trabalho. Por trabalhar como cabeleireiro por muitos anos, como dekassegui no Japão e como dono de um pequeno comércio de doces (que também fazia entregas) seu universo relacional era bem amplo, constituído de familiares, amigos, clientes e por vezes, pessoas desconhecidas que encontrava nos diferentes lugares que frequentava. Apesar de trabalhar durante a maior parte do dia, conseguia tempo livre para realizar atividades de lazer com familiares e amigos: viajava, pescava, andava de bicicleta, jogava sinuca, freqüentava parques, entre outras atividades. Sofreu o AVE aos 61 anos e as sequelas se estenderam pelo hemicorpo esquerdo. Era independente na locomoção em pequenas distâncias (dentro do domicílio) e necessitava do auxílio de sua esposa e neto para cuidar do mercadinho da família. Relatou também ser dependente para atividades de autocuidado e ressente-se pelo afastamento das atividades de lazer e visitas aos irmãos e amigos.

Mariana, com 62 anos, era casada e tinha 4 filhos. Aos 60 anos, passou por amputação no membro inferior (terço distal) devido a diabetes. Quando criança experienciou a perda de sua mãe e irmã caçula, situação que lhe causou grande sofrimento e que relatou com muita tristeza. Foi quem cuidou dos irmãos, porém mesmo com esta responsabilidade, era agredida fisicamente por seu pai e sua madrasta com freqüência. Para sair de casa, aos 15 anos, conseguiu uma ocupação como empregada doméstica e morava no local de trabalho. Casou-se aos 18 anos e logo depois optou por ser dona de casa. Antes da amputação cuidava de seus dois netos e de seu marido, cadeirante, que sofrera um AVE, anos antes. Gostava muito de andar pela rua e visitar sua filha, que mora em outra cidade. Sempre foi uma pessoa muito reservada e suas relações de convivência se restringiam aos seus dois filhos, genro, netos e grupo de hipertensão, que freqüentava uma vez por semana na UBS. Porém, após a amputação , não sai mais de casa sem auxílio. Deixou de participar das reuniões escolares da neta e do grupo de hipertensão, o que agora a faz esperar ansiosamente pela visita mensal da ACS. 
Na época da realização da entrevista, frequentava um Centro de Reabilitação três vezes por semana, onde fazia atividades de reabilitação e aguardava sua prótese na esperança de sozinha, poder sair de casa novamente.

Valquíria, com 31 anos, era solteira e cuidava de dois sobrinhos. Aos 15 anos ao sair da festa de uma amiga sofreu lesão medular por arma de fogo ficando paraplégica. Devido à gravidade de sua lesão e às condições precárias de cuidado (sua mãe trabalhava o dia todo e não havia outra pessoa disponível), até os 19 anos realizou diferentes tratamentos em hospitais e centros de reabilitação. Assim sendo, os profissionais de saúde se constituíram como parte importante de seu círculo social e quando deixou de freqüentar essas instituições teve uma redução drástica das suas relações de convivência, passando a maior parte dos dias dentro de casa. Quando entrevistada morava em área de ocupação na região da UBS, porém mantinha contato com os seus vizinhos da época em que morou em Osasco e com algumas pessoas da Igreja, que frequentava quando conseguia alguém que a levasse. Locomovia-se somente por meio de cadeira de rodas, o que limitava sua autonomia. Diferentemente de antes da lesão não saia mais de casa para lazer, pois, dependia de outros devido às barreiras arquitetônicas. Aos sábados costumava trabalhar em outro bairro como "guardadora de carros", e sua locomoção se dava através de ajuda dos vizinhos que lhe ofereciam carona. . Referiu que gostaria de trabalhar em emprego formal para sustentar seus familiares (principalmente sua mãe) e voltar a frequentar a Igreja.

Fernanda, com 46 anos, é divorciada e tem dois filhos. Trabalhou muitos anos como cobradora de ônibus e antes do AVE trabalhava como auxiliar de enfermagem e estudava aos finais de semana. Assim como Shin, seu círculo social era vinculado às pessoas do trabalho, porém seu tempo livre era escasso, já que trabalhava e estudava (inclusive aos finais de semana). Assim sendo, quem cuidava de seus filhos era a sua mãe.. Frequentemente os encontrava nos momentos de lazer, tais como jantares aos finais de semana ou ainda quando não ia à escola. Algumas vezes, saia com as amigas de trabalho para conversar. Sofreu AVE aos 38 anos. Apresentava sequelas cognitivas (perda da memória de curta duração, episódica e de orientação espacial), e físicas (perda da força muscular). Seu marido a abandonou, logo após o episódio. Agora mora com seu filho mais novo, no mesmo terreno onde mora sua mãe e outra irmã. Saia poucas vezes de casa, porque necessitava de acompanhante o que limitava sua circulação a visitas ao médico ou a Igreja aos domingos Sentia falta da rotina de trabalho, dos colegas e das reuniões com os amigos.

\section{Aquisição da deficiência e alterações das relações de convivência}

O conhecimento das histórias de vida possibilitou realizar recortes onde foi possível identificar a importância das relações de convivência estabelecidas durante a vida pelos entrevistados.

A diminuição das relações de convivência apareceu como determinante da condição de saúde da pessoa após o episódio da deficiência. As esferas das relações interpessoais construídas durante a vida, no trabalho, na vida comunitária e com os familiares e as atividades lazer foram comprometidas. O impacto foi direto sobre diferentes aspectos da vida e, por vezes, ampliou o isolamento social influenciado pelas barreiras arquitetônicas e sociais, usualmente encontradas no dia-a-dia.

Nas narrativas, os entrevistados apontaram que além das sequelas funcionais, a aquisição da deficiência gerou impedimentos significativos nas relações de convivência estabelecidas durante a vida. Percebeu-se a interrupção destas relações em decorrência do afastamento do trabalho e das dificuldades de circulação social.

A desvinculação do mundo do trabalho dificultada pelas condições precárias de circulação, mobilidade reduzida e pela própria condição de incapacidade física, resultou no afastamento dos entrevistados do universo de trocas sociais promovidas pelo simples fato de sair de casa para ir ao trabalho.

Antes da deficiência, Fernanda tinha muitos amigos, não só em decorrência do trabalho, mas também por freqüentar diferentes equipamentos que promoviam as trocas sociais, como a escola e os diferentes hospitais em que trabalhava; agora nesta nova fase sofre com as dificuldades de circulação social:

Eu acho que eu me divertia bastante, então eu não sei mais falar o termo me divertir mais. Porque hoje tudo é difícil. Paquerar. Ir a um baile. Ir a um forró. Ter amigos entendeu? (Fernanda, p. 12).

Além disso, o afastamento do trabalho resultou uma diminuição da possibilidade de vivenciar novas experiências, exercer a criatividade e circular por diferentes lugares:

Eu e minha esposa andamos para muitos lugares. Fomos para o lado do litoral lá na Praia Grande, porque naqueles lados eles vendem muitas queijadinhas na praia. A gente ia lá para pesquisar, até que eu conheci uma pessoa que fazia também. Eu ia às vezes à fábrica dele e ficava de olho em como era o negócio [risos]. Aí, no começo, a gente estragava tudo, até aprender o que ia e o que não ia à massa para dar a consistência, o ponto. A gente não 
FERREIRA, T. G.; OLIVER, F. C. A atenção domiciliar. Rev. Ter. Ocup. Univ. São Paulo, v. 21, n. 3, p. 189-197, set./dez. 2010.

sabia se ia fermento ou não para fazer crescer, mas não vai não. Só que eu não vou te contar o segredo também, não risos. Depois que deu certo, comprei um forno industrial e comecei a vender lá nos Jardins, mas aqui também muita gente comprava. Quando eu começava a assar de manhã, aquele cheiro ia para a COHAB inteira. Tem muita gente que pergunta por que não tem mais queijadinha e eu falo que porque agora eu não posso fazer, porque depende de usar as duas mãos assim, para tudo (SHIN, p.70-71).

Como é observado no depoimento acima, a aquisição da deficiência acarretou na diminuição da circulação social, reduziu significativamente as oportunidades de se conhecer outras pessoas e usufruir socialmente das relações conquistadas no dia-a-dia tal como conversar e/ou ter contato com outras pessoas. Não exercer um ofício, por vezes, ampliou a frustração e reforçou o sentimento de solidão e o isolamento social. Para Fernanda a diminuição do convívio com estranhos provoca saudades da época em que trabalhava:

Ah! Sinto saudades do cheiro do hospital, das pessoas. Eu gostava muito de trabalhar com pessoas, entendeu? Então, aí... Então, eu tirava sangue, mas eu não ficava assim, que tem aquelas pessoas que tem fila para tirar sangue no hospital, eu ia à UTI. Eu ia à HOPE (Casa Hope). Eu ia ao centro cirúrgico, entendeu? (Fernanda, p. 22). Para Fernanda, conviver com estranhos e amigos fazia parte de sua rotina e após a aquisição da deficiência, parou de circular em diferentes espaços como bares, cinemas, escola, entre outros. Isto significou diminuição das oportunidades de lazer e de conhecer novas pessoas

Houve considerável diminuição do círculo social, porém não o isolamento completo destas pessoas. Como consequência da deficiência, pode-se citar o afastamento dos espaços de circulação, diminuição dos contatos com estranhos, a ampliação do tempo solitário e o afastamento de familiares e amigos.

Eu gostava tanto de andar e ir ao postinho. Conversava com as meninas. Fazia a maior bagunça com as meninas. Hoje eu fico aqui entocada nesta casa sem poder sair. Sem poder com ninguém (Mariana, p. 28).

A deficiência provocou angústia ao ressaltar o valor da liberdade, que agora foi perdida. Em muitas narrativas a falta de locomoção sugere cárcere, isolamento, dependência.

Eu também estou na cadeira de rodas, estou presa. Se ninguém me levar em um canto eu não posso ir. Não posso fazer escala para canto nenhum (Valquíria, p.6).

Não há contato com o mundo fora do domicílio. Há o desejo, porém impedido. As rupturas se tornam mais perceptíveis quando a circulação é limitada. A ausência de lugares para se conviver se torna mais aparente

\begin{abstract}
Eu ia à escola, levava a minha neta. Naquele tempo ela estava no pré lá em cima, não é? Ela estava na creche. Eu participava de tudo, porque o pai dela não estava nem aí. Não entendia muito dessas coisas. E eu gostava de ir. Reunião, tudo, eu gostava de ir. Que eu queria saber! Lá elas conversavam, ficavam falando as coisas de criança. Eram tudo essas bobageirinhas, sabe? Que as crianças não podiam ir sem uniforme, que as crianças não podiam ir como o cabelo desamarrado, e tudo essas coisas, não é? Ia lá para escutar, não é? Que eu gostava de ir mesmo, não é? Gostava sim. Eu participava de tudo. Agora eu não posso. Levava ela, buscava. Gostava de ir levar, buscar ela. Agora eu não posso fazer nada disso (Mariana, p. 14).
\end{abstract}

A partir da compreensão da importância das relações de convivência, é necessário se pensar em estratégias para a ampliação e consolidação das mesmas. Desta maneira, a atenção domiciliar pode ser uma intervenção vantajosa, pois possibilita ao terapeuta ocupacional se aproximar da realidade da pessoa com deficiência e compreender sua situação de vida. Este entendimento pode auxiliar na construção de propostas tanto para conhecer como para ativar a rede social.

\section{Atenção domiciliar como proposta de ativação das re- lações de convivência}

As condições observadas, tais como o afastamento promovido pela interrupção das relações de trabalho da vida comunitária e também pelas características descritas da atenção domiciliar, é possível sugeri-la como uma viável alternativa de atenção em saúde já que pode oferecer ao terapeuta instrumentos para reconhecer e contemplar as questões identificadas anteriormente com vistas ao acompanhamento de pessoas com deficiência e assim construir uma abordagem em Terapia Ocupacional.

Rogers et al. (1997), ressaltam a importância da atuação do terapeuta ocupacional no domicílio, pois é oportunidade do mesmo avaliar e identificar problemas de desempenho da pessoa com deficiência no seu contexto natural, visualizar tarefas que são usuais e importantes, determinar o plano de tratamento levando em conta o prognóstico relacionado à deficiência e traçar estratégias condizentes com as necessidades mais urgentes do paciente. Também enfatizam a importância do paciente como participante da construção do processo terapêutico. Destacam que a qualidade da terapia depende do quanto o paciente reconhece suas incapacidades, necessidades e participa decidindo como e o que quer resolver/sanar, dessa forma deixa de ser paciente 
para estabelecer uma parceria com o terapeuta.

Ao atuar no domicílio o terapeuta primeiramente pode reconhecer a rede social significativa (SLUZKI, 1997) e depois auxiliar na ativação desta rede como, por exemplo, pode estimular a realização de contatos telefônicos, auxiliar o reencontro com vizinhos, organizar reuniões familiares para lidar com os problemas enfrentados pela pessoa e ampliar o seu contato com os mesmos, ou ainda favorecer a participação das pessoas em equipamentos sociais do território, além de cuidar das questões ligadas à minimização de sequelas e ampliação da funcionalidade.

A formação do terapeuta ocupacional favorece a atuação voltada à identificação e ativação e/ou construção de espaços que possibilitem trocas sociais baseadas no respeito às diferenças, ainda que estes não sejam os espaços formalmente constituídos com essa finalidade. A casa, a vizinhança, a comunidade são repletos de recursos informais que, quando ativados, podem se constituir em poderosos aliados do processo: pessoas, objetos e espaços (SIEGMAN et al., 2002, p. 42).

Baum e Law (1998) colocam que desta maneira o terapeuta ocupacional em vez de focalizar a atenção somente no indivíduo, pode, na medida do possível, buscar o desenvolvimento e a manutenção da independência da pessoa com deficiência na comunidade.

Vale salientar que como a pessoa com deficiência geralmente desconhece suas possibilidades, devido ao caráter inédito da experiência, comumente focaliza sua atenção nas suas incapacidades, assim sendo, o trabalho do terapeuta ocupacional a partir da intervenção no domicílio, pode favorecer o empoderamento destas pessoas e proporcionar um processo onde elas consigam compreender essa nova condição, colaborar criando estratégias para lidar com as adversidades e assim gerar e /ou ampliar as relações de convívio.

Essa nova forma de parceria requer que o terapeuta reconheça o saber da pessoa e contribua proporcionando a escuta e a informação de que precisa, de maneira a construir uma relação onde se estimule a troca de experiências a fim de ampliar a participação da pessoa com deficiência neste processo de adaptação a sua nova condição de vida . Desta forma o indivíduo pode se empoderar e iniciar um controle sobre alguns aspectos de sua vida (WILKINS et al., 2001).

Iniciativas na comunidade tais como grupos de convivência e de geração de renda e trabalho, podem representar alternativas para o enfrentamento da solidão e possibilidade de acessar remuneração, em alguns casos, essencial para a qualidade de vida cotidiana. Além disso, realizar uma nova atividade significativa poder diminuir a sensação de incapacidade, o que pode representar ganhos significativos para a autoestima e a qualidade de vida.

$\mathrm{O}$ apoio para o ingresso em ambientes, que promovam trocas sociais é de suma importância. Conhecer os espaços de convivência do bairro e possibilidades de tecer uma rede de apoio pode ser uma alternativa viável para a inclusão das pessoas nestes locais

Para algumas pessoas com deficiência são escassas as possibilidades de realizar atividades de lazer ou mesmo "estar" com outras pessoas e, consequentemente, o tempo solitário é maior que o tempo do convívio. Isto significa que além de passarem longos períodos do dia solitárias dentro de casa, enfrentam as limitações decorrentes da deficiência. Assim, promover a inserção em ambientes, que incentivem o exercício da participação pode ser de fundamental importância para a diminuição do isolamento e para adaptação a esta nova condição.

Desta maneira, é estratégia importante reconhecer este cenário pelo contato no domicílio e na comunidade a fim de ampliar as oportunidades de convívio e com isto diminuir o impacto causado pela deficiência na vida destas pessoas.

$\mathrm{Na}$ atenção domiciliar o terapeuta ocupacional pode se aproximar do cotidiano da pessoa com deficiência e ampliar possibilidades de compreendê-la no domicílio, no ambiente físico, na rotina e nas relações familiares. É possível também conhecer o contexto social, fazer contato com equipamentos sociais, que podem ser articulados para possibilitar caminhos para inserção e ampliação da rede social e de suporte das pessoas com deficiência.

Supõe-se que com esta aproximação com a realidade direta da experiência diária da deficiência o terapeuta possa construir uma visão contextualizada do que é "ser deficiente" e assim consiga atuar de maneira mais condizente com essa realidade, focalizando suas intervenções para a superação das principais barreiras que a pessoa com deficiência enfrenta. Assim, o terapeuta ocupacional terá subsídios para construir uma parceria com a pessoa com deficiência e sua família, que vislumbre as possibilidades de reestruturação da vida diária de modo a extrair dela experiências mais recompensadoras e o engajamento em atividades que sejam estimulantes e interessantes e que ampliem o significado de sua existência.

\section{CONSIDERAÇÕES FINAIS}

Quando as concepções sobre a própria reabilitação e sobre os indivíduos de que dela dependem são alteradas, ampliam-se as possibilidades de estabelecer uma compreensão sobre o cotidiano no qual essas pessoas estão inse- 
ridas, sua situação de vida, seus projetos, e suas relações de convivência (elemento importante para a manutenção e cuidados de pessoas com deficiência). Ao valorizar estas relações é possível se instituir uma atuação profissional contextualizada pelas necessidades cotidianas e com isto ampliar oportunidades de participação e possibilitar a conquista da autonomia necessária à ampliação da qualidade de vida.

Pelas condições observadas em decorrência da aquisição da deficiência, tais como isolamento, dificuldades de mobilidade, diminuição do círculo social e pelo afastamento da experiência de trabalho e da vida comunitária, é possível sugerir a atenção domiciliar como uma alternativa de atenção em saúde, que reconheça e contemple as questões identificadas anteriormente, a fim de desenvolver uma abordagem em Terapia Ocupacional, que objetive, não mais apenas, a ampliação das capacidades físicas, mas também ofereça suportes para que as pessoas possam sentir novamente o prazer de estar junto, de conversar longamente, de afirmar sua diferença através da convivência.

Nas experiências comunitárias e/ou territoriais é necessário que os serviços se estruturem no sentido da equiparação de oportunidades para que seja possível realizar uma atenção diferenciada. A intervenção pode assumir as orientações da atenção básica em saúde e assim permitir às pessoas com deficiências, que estão em situação de isolamento social, a conquista de novos vínculos e a reconstrução de seus laços de convívio. Desta maneira, a ampliação da rede social significativa pode resultar na diminuição do impacto da deficiência na vida diária.

FERREIRA, T. G.; OLIVER, F. C. Domiciliary care as a strategy for expanding the social relations of people with physical disabilities. Rev. Ter. Ocup. Univ. São Paulo, v. 21, n. 3, p. 189-197, set./dez. 2010.

ABSTRACT: This study discusses domiciliary care as a strategy that creates opportunities for people with physical disabilities to be with. We started from the assumption that after the acquisition of disability people have less opportunity to exercise this being with, by which we mean the possibility of being together, amongst and in a relation with something or someone, which can be a source of well-being and help the person adapt to the condition of living with disability. We intend to discuss the importance of being with for people with disabilities, and of domiciliary care as a strategy that allows knowledge and expansion of these social relations. We studied the life stories of four adults with acquired physical disabilities, living in the area of a basic health care unit in São Paulo, and which represented in gender, age and type of disability the people with disabilities identified in the unit. The life stories were transcribed and analyzed in order to learn about the importance of being with, before and after the acquisition of disability. Data analysis was based on significant social network theory. The decrease in social relations due to absence from work and decreased circulation heavily influenced the person's condition after the acquisition of disability. The understanding of disability as a social condition allows us to consider domiciliary care as an intervention strategy, which can assist in reducing isolation, expanding social and support networks and creating opportunities for social circulation, all of which can be seen to unfold from the act of being with.

KEY WORDS: Occupational therapy; Home visit; Disabled persons.

\section{REFERÊNCIAS}

ALMEIDA, M. C. Saúde e reabilitação de pessoas com deficiências: modelos assistenciais [tese]. Campinas: Faculdade de Ciências Médicas, UNICAMP, 2000.

AVALUND, K. Disability in old age. Longitudinal populationbased studies of the disablement process. Dan Med Bull., v. 51, p. 315-349, n. 4, 2004.

BAUM, C.; LAW, M. Community health: a responsability, an opportunity, and a fit for occupational therapy. Am. J. Occup. Ther., v. 52, n. 1, p. 7-10, 1988.

BRASIL. Ministério da Saúde. Internação domiciliar no âmbito 
do SUS. Portaria $\mathrm{n}^{\mathrm{o}} 2.529$ de 19 de Outubro de2006. Institui a internação domiciliar no âmbito do SUS. Brasília, 2006.

COHEN, S. Social relationships and health. Am. Psychol., v. 59, p. 676-684, 2004.

DOIMO, L. A.; DERNTL, A. M.; LAGO, O. C. O uso do tempo no cotidiano de mulheres idosas: um método indicador do estilo de vida de grupos populacionais. Ciênc. Saúde Coletiva, v. 13, n. 4, p. 1133-1142, 2008.

FERREIRA, T. G. Pessoas com deficiências: condições de convivência e possibilidade de atenção domiciliar [dissertação]. São Paulo: Faculdade de Medicina, Universidade de São Paulo, 2009.

GASPAR, J. C.; OLIVEIRA, M. A. C.; DUAYER, M. F. F.; GASPAR. Perfil dos pacientes com perdas funcionais e dependência atendidos pelo PSF no município de São Paulo. Rev. Esc. Enferm. USP, v. 41, n. 4, p. 619-628, 2007.

GLAT, R. Somos iguais a vocês: depoimentos de mulheres com deficiência mental. Rio de Janeiro: Agir, 1989.

JOVCHELOVITCH, S.; BAUER, M. W. Entrevista narrativa. In: BAUER, M. W.; GASKELL, G. Pesquisa qualitativa com texto, imagem e som: um manual prático. Petrópolis: Vozes, 2002.

LACERDA, M. R.; GIACOMOZZI, C. M.; OLINISKI, S. R.; TRUPPEL, T. C. Atenção à saúde no domicílio: modalidades que fundamentam sua prática. Saúde Soc., v. 15, n. 2, p. 88-95, 2006.
MAZZA, M. M. P. R. A visita domiciliária como instrumento de assistência de saúde. [Citado em 1 dez. 2008]. Disponível em: http://www.fsp.usp.br/MAZZA.htm.

MELETTI, S. M. F. O relato oral como recurso metodológico de pesquisa em educação. In: MARQUEZINE, M. C.; ALMEIDA, M. A.; OMOTE, S. Colóquios sobre pesquisa em educação especial. Londrina: Eduel, 2003. p. 1-10

PANTANO, L. La discapacidad cómo problema social: un enfoque sociológico: reflexiones y propuestas. Buenos Aires, EUDEBA, 1987.

ROGERS, C. R. Tornar-se pessoa. 4a ed. São Paulo: Martins Fontes, 1991.

ROGERS, J. C.; HOLM, M. B.; STONE, R. G. Evaluation of daily living tasks: the home care advantage. Am J Occup Ther., v. 51, n. 6, p. 410-422, 1997.

SIEGMAN, C.; PINHEIRO, C. A.; ALMEIDA, M. C. Terapia ocupacional e pacientes acamados: ações comunitárias baseadas na identificação de problemas. Rev. Ter. Ocup. Univ. São Paulo, v. 13, n. 1, p. 37-43, 2002.

SILBERKASTEN, M. La construccion imaginaria de la discapacidad. Buenos Aires: Topia Editorial, 2006.

SLUZKI, C. E. A rede social na prática sistêmica: alternativas terapêuticas. São Paulo: Casa do Psicólogo, 1997.

WILKINS, S.; POLLOCK, N.; ROCHON, S.; LAW, M. Implementing client-centred pratice: why is it so difficult to do? Can. J. Occup. Ther., v. 68, n. 2, p. 70-79, 2001. 